Título:

\title{
EMPRESAS DE CARA A LA CRISIS POR LA PANDEMIA GENERADA POR EL COVID-19
}

\section{Docente: Sandoval Gómez Sara Teresa, sarasandoval@usantotomas.edu.co}

\section{Estudiantes:}

Sebastián Bustos

Luis Felipe Benítez

Michael Yesid Niño

\section{Espacios Académicos:}

Análisis y Comportamiento Organizacional

Habilidades Gerenciales - Coaching

\section{Resumen:}

Durante el primer periodo académico de 2020, el área de Talento humano del programa de Administración de Empresas de la USTA realizó dos foros virtuales con empresarios nacionales y extranjeros y con Gerentes de Talento Humano, para conocer las estrategias que se adelantan en relación con el talento humano para enfrentar la crisis desatada por la llagada del COVID 19.

En los ensayos realizados por los estudiantes de Análisis y Comportamiento Organizacional y Habilidades Gerenciales se presentan las principales percepciones de los estudiantes asistentes a los eventos frente a los conceptos desarrollados durante el semestre.

Dentro de los aspectos destacados fueron:

a. Las empresas deben reinventarse a medida que surgen nuevos cambios, por ende, los gerentes deben tomar decisiones importantes para el Bienestar de la Organización y de sus empleados.

b. Uno de los aspectos más importantes del Coaching que deben aplicar los empresarios en su rol de líderes es acompañar y fortalecer las habilidades de todos sus colaboradores para lograr un crecimiento individual y por ende grupal y así lograr el cumplimiento de los objetivos institucionales.

c. Dentro del tiempo de crisis en las organizaciones es fundamental desarrollar el hábito de la Proactividad, con el fin de superar las crisis conjuntamente entre los colaboradores no perdiendo la Identidad Corporativa., sino por el contrario afianzando los metas institucionales.

d. Retos del Gestor del Talento Humano en las Organizaciones.

e. Estrategias futuras para implementación después del COVID

Palabras Claves: Retos, Crisis, Adaptación, Liderazgo. 